\title{
Study on the Return to Natural Aesthetic Implication of Shen Congwen and Thoreau
}

\author{
Youping $\mathrm{Xu}^{1, \mathrm{a}}$ \\ ${ }^{1}$ Neijiang Normal University,school of Foreign Languages Neijiang ,641112, China \\ ${ }^{\mathrm{a}}$ email
}

Keywords: Shen Congwen, Thoreau, Return to Nature, Aesthetic Implication, Walden, Border Town

\begin{abstract}
Shen Congwen and Thoreau as the United States and China natural literary school representatives, literature has a very distinct aesthetic pursuit of return to nature. Based on this article, first outlined the Shen Congwen and Thoreau return to natural aesthetic implication triple values, including the return to the natural environment, criticism of modern civilization, the pursuit of spiritual home, followed by analysis of Shen Congwen and return to nature Thoreau Several different aesthetic implication including Heaven and nature-oriented, natural nourishment and natural temper, the transformation of society and social criticism, and finally from the living environment as well as the ideological basis of the angle, discusses the specific reasons both aesthetic implication different.
\end{abstract}

\section{Introduction}

Thoreau's literary representative of the height of the American Industrial Revolution, Shen is one of the leaders of modern Chinese literature, not only between the two country are different, life's also a difference of nearly a century, however, as Western literary giants, two who in literature but it has many similarities, one of the most typical is the return to natural aesthetic implication. Thoreau's "Walden" and Shen Congwen "river", "Border Town" and other works, spends much ink to return to nature. Nature is not just for their correction or criticism of the current civilization weapon, but their inner quest. Of course, due to the different living environment and the ideological basis of other factors, both return to natural aesthetic implication there are some differences, both authors personal differences. This difference is the difference between Western culture. Based on this article, Shen Congwen and Thoreau to return to natural aesthetic implication do the appropriate research.

\section{Shen Congwen and Thoreau Return to Natural Aesthetic Value Implication}

After the Industrial Revolution, humans and nature along the way a lot of changes, everything becomes possible, conquer nature become temporary clamor Sheng slogan, this concept was introduced to China through war, trade and other channels, it caused no small impact, but also with to some negative factors. Thoreau lived in the rapid development of the first industrial revolution, while the US economy take off, the phenomenon of increasing environmental pollution, which raises concerns Thoreau. In Thoreau, human nature is the same part of the Earth's equality, the rights of every animal, every plant as well as other natural species has to survive. Thus, humans can not because of selfish desire and ask to excessive nature, this will inevitably result in the Earth organism imbalance, leading to all kinds of disaster. Shen Congwen although unlike Thoreau industrial development brought about by the crisis so profound nature of cognition, but his departure from the natural beauty and humanity, advocates returning to the natural ecology. Shen from natural wen is full of humanity, such as "Border Town" in the understanding of bamboo forest, full of spirituality yellow dog, read the best of the vicissitudes of the White Tower and the like. Moreover, the "Border Town" where the characters are naturalized with features, the most typical is the portrayal of Tracy, "black and reddish skin naturally become", "thorough clear as crystal eyes" will man and nature skillfully blend [1]. 
Development of production technology will inevitably bring changes in social patterns, the rise of the industrial revolution and the development of a strong promotion of the growth of American bourgeois industrial civilization. Meanwhile, the industrial civilization has caused many people thought the confusion, the most typical is consumerism, hedonism prevalent. Thoreau lived in the United States before the Civil War, slavery industrial prosperity and coexistence, which Thoreau "Civilization is rooted in nature must be" thinking very different, as Thoreau staunch abolitionist who strongly condemned slavery, social development must be pointed out based on the harmonious development of man, nature and society. [2] In order to practice this ideal, Thoreau to Walden belly life for two years, its purpose is to show the world, the simple life can also be very happy, happy. Coincidentally, Shen industrial development of modern civilization system also formed more than a criticism. Shen Congwen Xiangxi early life in the countryside, was removed after Beijing, Shanghai and other big cities, city life to country life and have experienced. But Shen believes that urban life "for the money under the control of" hypocrisy, hypocritical. Thus its literary works of naturalized lifestyle, and harmonious interpersonal relationships more than a pursuit. Take the "Border Town" as an example, the book scene is tranquil countryside, plot is dull like water, but it can inadvertently sketched out pastoral atmosphere.

Spiritual crisis is a common feature of modern man. Progress and social development of science and technology is not fundamentally eliminate the human spirit more and more serious crisis. The human spiritual world and the natural world and the social form inseparable, spiritual crisis also stems from the natural and social crisis. Thoreau profound awareness to this point, which stand for the restoration of the intimate relationship between man and nature, and thus return to the human spirit home. In Thoreau, nature is full of spirit and spirituality, as long as the person being immersed in nature, with nature breathing, can cleanse the soul, to re-invent themselves. Thus Thoreau initiative Hermitage from the bustle of the city to the quiet of Walden, religiously respected worship nature. In the years Walden, Thoreau felt an unprecedented happiness. Shen Congwen also natural as the final destination of the human spirit home, man and nature live in harmony ecological consciousness in Shen Congwen's novels a consistent. Shen Cong - wen Western world, like a paradise, people in their daily live, and Valuing Loyalty, outspoken nature, and industrial society, the business community's indifference relationships starker. Shen Congwen believe natural scenery, local culture and improve the function of human nature, want a simple, natural and harmonious interpersonal relationships to correct the distortions of urban humanity, calling natural and moral regression.

\section{Shen Congwen and Thoreau Return to Natural Aesthetic Implication Distinction}

Shen Congwen and Thoreau described the nature is human nature, but there are many different. Shen's natural and human society is the harmony of nature, with a term to describe the traditional Chinese thinking is "Heaven," Thoreau's nature is to break the balance of the relationship between man and nature, emphasis on basic natural independence the more pointed nature of subjectivity. Shen Congwen in many literary works depict natural scenery, whether prose or fiction, such as "fishing" in the description of the King dated the words "water bugs flying around in the moonlight, wings micro sound away the sound of the water at the beach like a mother comforts her child sleep eyes sing songs, "here, Shen Wen employer of the United States to describe the quiet of nature, showing the unity of nature and human equality relationship. Thoreau's view of nature is beyond the equality of barriers, not only pointed out the nature of subjectivity, more emphasis on its ontological, human society has become the natural appendage. In "Walden" in Thoreau to describe "I have heard the sound of a cough on the lake ice," highlights the life of the lake, and then he also pointed out that when "might be expelled from the Garden of Eden as far away as Adam and Eve, • • Walden has been in existence, "should follow the natural changes of the track, there is no association with human society, human nature is not subordinate to the contrary, subordinate to human nature.

Nature is not the same one, it has a diverse faces, flowers nature, stormy sea is a natural, gives a pleasing sense of the former, which nourish the soul, the latter gives a temper. Shen Congwen and natural face Thoreau saw was somewhat different. On Shen Congwen, he described the nature is 
human nature, is one of the natural nourishment, such as "Border Town" in relationships is rich in natural simplicity Xiangxi unique natural landscape has given birth, "rain", "mining fern "and other works of young men and women" do not do a little stupid "act, and lazy Yang Guan, warm spring breeze brings this natural care are closely linked. In contrast, natural Thoreau Works presents another style in the "walk" in Thoreau pointed out sharply that "nature, that is, with civil liberties and culture as opposed to absolute freedom and wildness," it is not human conquest, on the contrary there is a human conquest of wild. If Shen from natural wen is Juanjuan streams, refreshing, natural Thoreau's mind is boundless wilderness, uninhibited. [3] Thoreau believes that the current development of human civilization although the British aristocratic civilization, but at best be regarded as "inbreeding" results, no future. And hope in the future of mankind "impenetrable" the swamp, return to the wilderness, to regain the wild is the only option to correct the ills of the current civilization.

Shen's novels, society has multiple forms, the "three-three", "Border Town", the human society is the simple peace and harmony, and in the "councilor", "Da-phase", the human society has contracted fall, worships money and other ills, the reason why this happens, and modern civilization pervasive penetration in rural areas are closely related. Shen Congwen depends on this phenomenon as "diseases of civilization", since it is a disease, then there is cure. Shen from the text of the prescription is given back to nature, of human nature by replying to reconstruct the harmony between man and nature relationship. Here, Shen neither blindly advocate returned to the wild state, not respected live in a purely natural way, the knowledge that he hopes to draw nutrients from the nature of social life. This Thoreau and Shen Congwen is different. Thoreau Society uphold the comprehensive critical attitude towards nature is a high degree of praise and worship, even to the point where, regardless of principle. As its "Natural History of Massachusetts" as stressed, "you can not find in society, health, only to be found in natural health", is completely natural and social dichotomy, nature is the perfect body, modern civilization off society is a natural track traitor, is the object, we need to set things right from a natural perspective.

\section{Cause of Difference Formation in Shen Congwen and Thoreau Return to Natural Aesthetic Implication}

Shen from the Unique living experience makes him the label character Chinese modern literary history Local Literature, and Shen Congwen literature and Lu Xun numbness, ignorant, cruel countryside style there are different, the idyllic local scenery. Shen Congwen was born in Phoenix, fourteen years before had been spent in Phoenix, Phoenix beautiful scenery and honest relationships to young Shencongwen left a deep impression, which is the novel concentrated intractable Local Complex the main reason, Shen often show their works in Western customs, such as "Feng Zi," "Sentinel" which depicts worship and fetishism. At fourteen, Shen join ascended removed after Beijing, between Shanghai and major cities witnessed interpersonal strife and trade erosion of human nature, the more engrossed in natural scenery and local customs. [4] Thoreau lived in the mid-nineteenth century, the young American is at the peak of industrialization and economic development policies pursued by President Jackson and the civilian political movement in the country to create a mercantilist and material interests above everything else fashion of the time, and because of the rapid development of the westward movement, in the "quick success" of the state of American society as a whole, people think that is the daily pursuit of wealth. The core of human nature as a source of wealth in the United States while promoting economic development, but also brought great ecological crisis, the long-term development of human caused irreparable damage. Thoreau had a premonition that this point, we face this crisis by practicing activities during the life of Walden, Thoreau lived a simple life away from the money, to show the world a simple life and to be happy.

As mentioned earlier, Shen's view of nature and Thoreau's view of nature there is a big difference, of course, this can be attributed to both life background difference, and heterogeneity between the two ideological foundation also has great relevance. Shen from the text of the ideological basis mainly due to the following three points: First, Xiangxi area's unique history and culture, cultural 
customs. MAGICAL CULTURE IN CHU Xiangxi as an important area, has always been to the "spirits" and well-known. Miao Chu is a relict of the nation, the ghost of the wind more prevalent, Shen grew up in western Hunan, the grandmother is the Miao people, which makes it Xiangxi world a "divine world"; Second, Chinese traditional Taoist culture. "Nature" is the core category of Taoism culture, emphasizing the people in their daily lives pure inaction, which Shen has a very important impact on the formation of the text from the concept of country life, as compared to the urban life of ingenuity, the country life more fit human nature; third, the impact of Western culture. As Jin Jiefu said, Shen Congwen under Western Romantic Literature deep impact, and many characters have the shadow of Western literature, Rousseau is a return to natural Shen Congwen Important Thought primer. Thoreau In addition to being a writer, or American Transcendentalism movement mainstay, Transcendentalism from the Puritan tradition, and in Puritanism advocates simplicity, nature is an important factor in the return to nature inspired Thoreau. Moreover supreme spirit of New Platonism, classical German philosophy on intuition and so has an important influence on Thoreau. [5] This enables the age of 28 Thoreau stood openly secular antithesis of seclusion Walden, practical action to wake the world.

\section{Conclusion}

Modern civilization from instrumental rationality, especially after two industrial revolutions, dramatic changes occurred in life of human society, Thoreau lived in between the first industrial revolution and the Second Industrial Revolution, Shen lives in the second after the industrial revolution, the development of technology have personally felt the alienation of man caused, people and even alienation between man and nature of industrial civilization. So, from their own perspective, a writer unique sensitivity to show the world the ideal state of existence, expressing a return to natural aesthetic implication pursuit.

\section{Acknowledgements}

Fund Project: Neijiang Normal University social science key research projects: Eco Thoreau "Walden" Criticism Thought (project number: 13SA02).

\section{References}

[1] Xu Siyou. question of modern civilization, to promote a return to nature - On Shen Congwen and Rousseau literary ideal Romantic Traits [J]. Chaohu Teachers College, 2012 (01): 74-78.

[2] Li Deyi, Sheng Chunyan, Yu Qian. Thoreau and Shen Congwen ecological resonance text [J]. theory of Observation, 2015 (12): 63-65.

[3] Ge Pei. Billy mild and wild - the difference between Shen Congwen and Thoreau described a "natural" [J]. Suzhou College of Education, 2015 (06): 44-47.

[4] Fan Shuhua Shen Congwen natural view and its reason [J]. Ankang University, 2009 (03): 67-69

[5] Zhu Gaoli. Yuanming and Thoreau return to natural aesthetic implication [D]. Northwest Normal University, 2009. 